\title{
Surface Investigations of Aluminum in 2M Hydrochloric Acid Solution in the Presence of Potassium Iodate Inhibitor
}

\author{
A.A. El Maghraby*
}

Chemistry Department, Faculty of Science, Cairo University, Giza, Egypt

\begin{abstract}
The results of investigations by using optical, scanning electron microscopy (SEM) and energy dispersive Xray spectroscopy (EDS) to study the surface morphology, the composition of adsorbed film formed on the surface of aluminum samples in $2 \mathrm{M}$ hydrochloric acid solution containing $100 \mathrm{ppm}$ optimum $\mathrm{KIO}_{3}$ dose. The data reveal that the additive improves the surface morphology of aluminum, due to the marked layer enrichment of Al- surface by inhibitor components. Detailed studies were carried out to investigate the effect of oxygen in the inhibition process. The nature and strength of the passive film and the mechanism of its formation are explained based on detailed studies conducted under experimental conditions.
\end{abstract}

Keywords: Aluminum, $\mathrm{KIO}_{3}$, SEM, EDS, optical microscopy, corrosion inhibitor.

\section{INTRODUCTION}

Aluminum is considered as one of the most important metals due to its economic and technical importance as well as the wide range of industrial applications like reflectors, decorative products, buildings, airspace, aircraft and architectural [1]. It owns as excellent corrosion resistance and its usage as one of the primary metals of commerce due to the barrier oxide film that is bonded to its surface and that, if damaged it re- forms immediately in most environments.

The study of the corrosion of aluminum and its alloys is a subject of a pronounced importance because of its widespread applications in many industries. Aluminum is reactive metal $\left(\mathrm{E}^{\mathrm{O}}=-1.66 \mathrm{Vs} \mathrm{NHE}\right)$, its resistance to corrosion in solutions of $\mathrm{pH}$ between 4- 9 in presence of chloride ions is weak [2]. This corrosion resistance is attributed to the presence of this; adherent and protective surface oxide film. Above and below this $\mathrm{pH}$ range, solubility of the oxide film increases, and aluminum exhibits uniform attack [3]. In addition to corrosion resistance, other properties are colorless and nontoxic corrosion products, appearance, electrical and thermal conductivity, reflectivity and lightness or good strength or weight ratio [3].

Aluminum when introduced in acids after air exposure exhibits a period of induction, which is due to the slow dissolution of the film. Pure aluminum has many longer induction periods than impure metal for the sites of impurities constitute defects in the film [4]. The formed film on aluminum metal is amphoteric in nature and dissolves in strong acids and alkalis, resulting in varying rates of corrosion of the metal [5].

Hydrochloric acid solutions are used for pickling of $\mathrm{Al}$ and Al-alloys and for chemical or electrochemical etching of Al foil and lithographic plates used as substitutes for zinc

*Address correspondence to this author at the Chemistry department, Faculty of Science, Cairo University, Giza, Egypt; Tel: +2012 098102; Fax: +2 02 35727556; E-mail: maghraby04@yahoo.com
[6]. Since, the metal dissolution in such solutions is rather large, it is necessary to inhibit it by the addition of inhibitors which effectively eliminate the undesirable destructive effect of acids on the base metal and improve etching qualities and provide good pickled metal surface [7].

Inhibitors are chemicals that directly or indirectly coat a film on a metal surface to protect it from its environment [8]. Most inhibitors are adsorbed by the metal surface from a solution or dispersed, but some are applied directly as a coating [9]. Generally, the dissolution of metal can be suppressed by the action of adsorptive inhibitors which may prevent the adsorption of the aggressive ions, and by the formation of a more resistant film on the metallic surface [7].

The previous work [10] studied potassium iodate as an effective corrosion inhibitor for aluminum in $2 \mathrm{M} \mathrm{HCl}$ solution. In this context, the present work has additional aim to clarify the nature of the protective film by surface analytical techniques (SEM and EDS) in addition to optical microscopy. The adsorption mechanism of $\mathrm{KIO}_{3}$ on the aluminum surface in $2 \mathrm{M} \mathrm{HCl}$ has been discussed.

\section{2- EXPERIMENTAL}

Specimens measuring $(10 \mathrm{~mm} \times 10 \mathrm{~mm} \times 2 \mathrm{~mm})$ cut from pure $99.99 \%$ aluminum sample were used. These were polished with emery papers (200-1000 grades), degreased in acetone, and washed by distilled water before introduction into the solutions. Experiments were conducted in $2 \mathrm{M} \mathrm{HCl}$ $(\mathrm{pH} \approx-0.28)$ alone, and with $100 \mathrm{ppm} \mathrm{KIO}_{3}$ inhibitor optimum dose. Examination of Al- surface in $2 \mathrm{M} \mathrm{HCl}$ and after exposure to inhibited acidic solution (1h immersion) was carried out using optical polarizing microscope (Nikon, Japan) attached with control box and camera AFX IIA. The compositions of all surface elements were identified by energy dispersive X- ray spectroscopy (EDS) with $\mathrm{Cu} \mathrm{K}_{\alpha}$ radiation at $35 \mathrm{KV}$. The electrode surface of aluminum was examined by SEM (Scanning Electron Microscope-JSMT20- JEOL. Japan) before and after immersion in the test solution in the absence and presence of $\mathrm{KIO}_{3}$ inhibitor at room temperature for $1 \mathrm{~h}$. 


\section{3- RESULTS AND DISCUSSION}

\subsection{Optical and SEM Investigations}

The results of morphology investigation of aluminum surface examined by SEM before and after treatment in $2 \mathrm{M}$ $\mathrm{HCl}$ in the absence and presence of $100 \mathrm{ppm} \mathrm{KIO}_{3}$ are shown in Figs. (1-3). Investigation of the scanning electron micrographs of mechanically polished $\mathrm{Al}$ electrode without any treatment (clean sample, Fig. 1) shows that $\mathrm{Al}$ sample treated with $2 \mathrm{M} \mathrm{HCl}$ (Fig. 2) has corrosion areas on its polished surface, which do not exist on the clear sample. The presence of such regions can be attributed to the dissolution of Al due to the surface attack by the aggressive chloride ions.

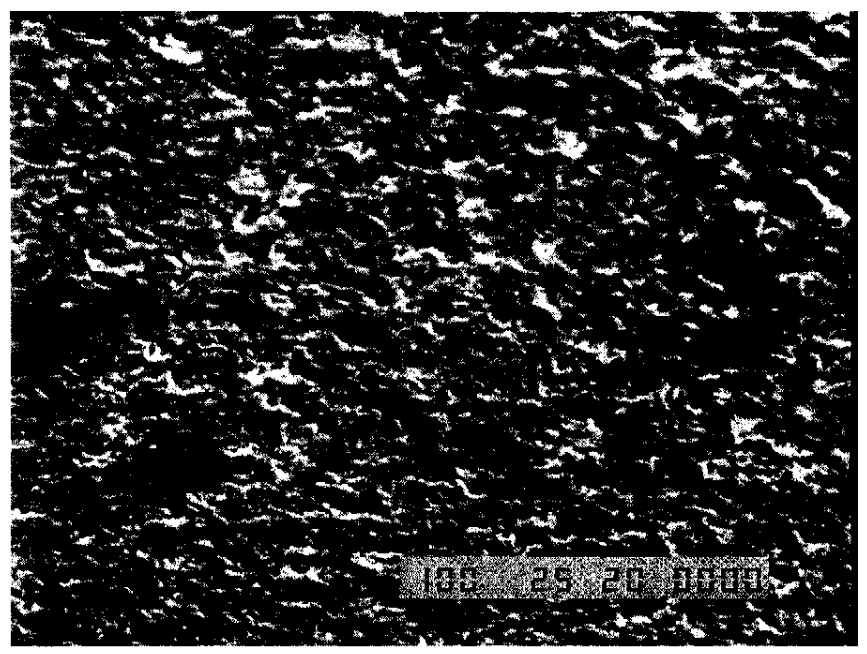

Fig. (1). SEM micrograph of clean Al sample $X_{100}$.

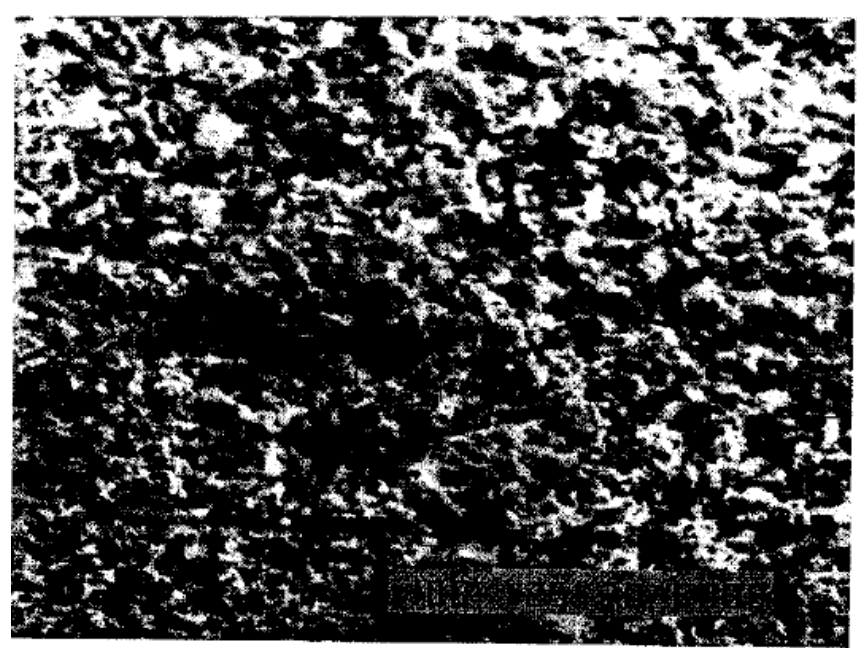

Fig. (2). SEM micrograph of $\mathrm{Al}$ sample immersed in $2 \mathrm{M} \mathrm{HCl}$ for $1 \mathrm{~h}, \mathrm{X}_{100}$.

Immersion of the $\mathrm{Al}$ sample in $2 \mathrm{M} \mathrm{HCl}$ solution containing 100 ppm $\mathrm{KIO}_{3}$ (Fig. 3), shows that there is an improvement in the surface morphology, possibly by diminishing the corrosion areas due to covering of the active sites. This process leads in turn to the coverage of the surface by protective film. This explains why the corrosion rate of $\mathrm{Al}$ in $2 \mathrm{M} \mathrm{HCl}$ in the presence of $100 \mathrm{ppm} \mathrm{KIO}_{3}$ is lower than that measured in inhibitor- free solution [10]. The same observations are obtained in optical microscopy of the samples (Figs. 4-6).

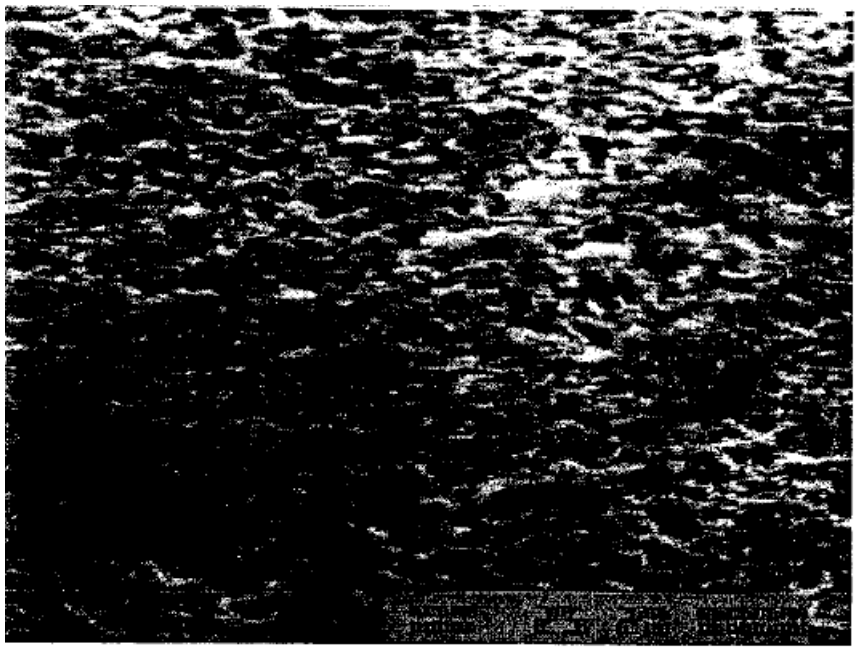

Fig. (3). SEM micrograph of $\mathrm{Al}$ sample immersed in $2 \mathrm{M} \mathrm{HCl}$ containing $100 \mathrm{ppm} \mathrm{KIO}_{3}$ inhibitor for $1 \mathrm{~h}, \mathrm{X}_{100}$.

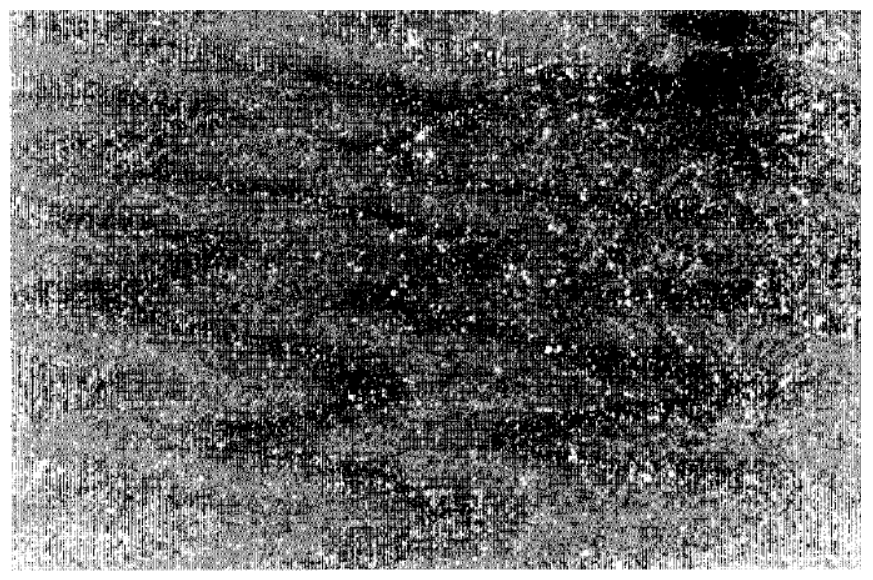

Fig. (4). Optical micrograph of pure $A l$ sample, $X_{10}$.

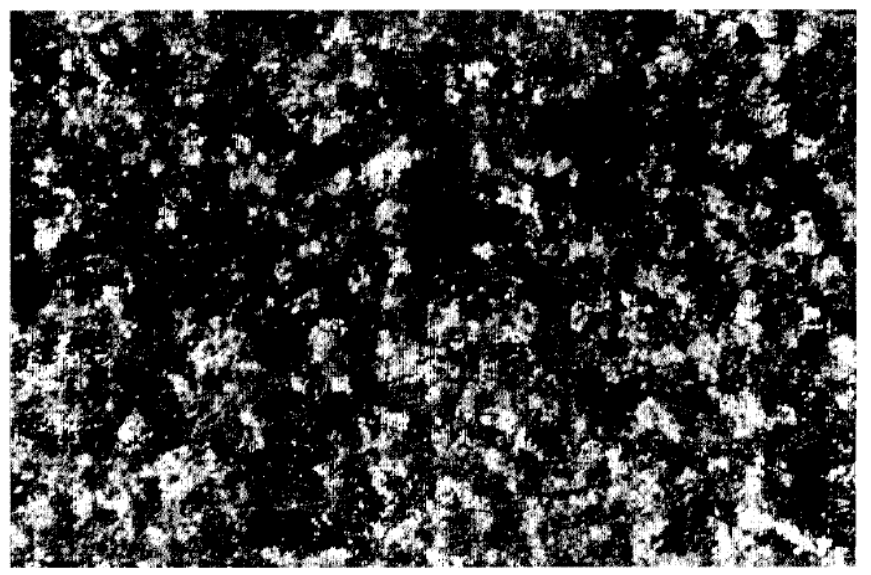

Fig. (5). Optical micrograph of $\mathrm{Al}$ sample immersed in $2 \mathrm{M} \mathrm{HCl}$, $\mathrm{X}_{10}$.

\subsection{EDS Measurements}

The EDS spectra for pure Al sample (Fig. 7) show clear peaks for the main constituents $22.27 \% \mathrm{O}$ and $57.51 \% \mathrm{Al}$. On the other hand, the EDS spectra of Al sample immersed in $2 \mathrm{M} \mathrm{HCl}$ for 1 hour (Fig. 8) show elemental 8.32\% $\mathrm{O}$ and 91.68\% Al composition. The elemental composition of $\mathrm{Al}$ surface immersed in $2 \mathrm{M} \mathrm{HCl}$ in the presence of $100 \mathrm{ppm}$ $\mathrm{KIO}_{3}$ inhibitor show an increase in oxygen percent and 
decrease in aluminum percent $(11.05 \% \mathrm{O} \& 88.95 \% \mathrm{Al})$ which indicates the oxidative inhibition of $\mathrm{KIO}_{3}$ inhibitor to aluminum surface (Fig. 9).

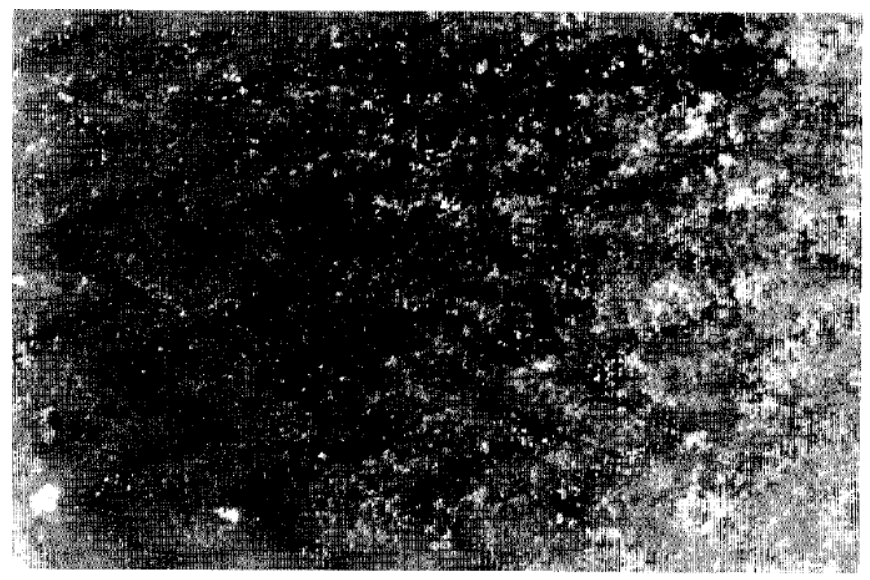

Fig. (6). Optical micrograph of Al sample immersed in $2 \mathrm{M} \mathrm{HCl}$ containing $100 \mathrm{ppm} \mathrm{KIO}_{3}, \mathrm{X}_{10}$.

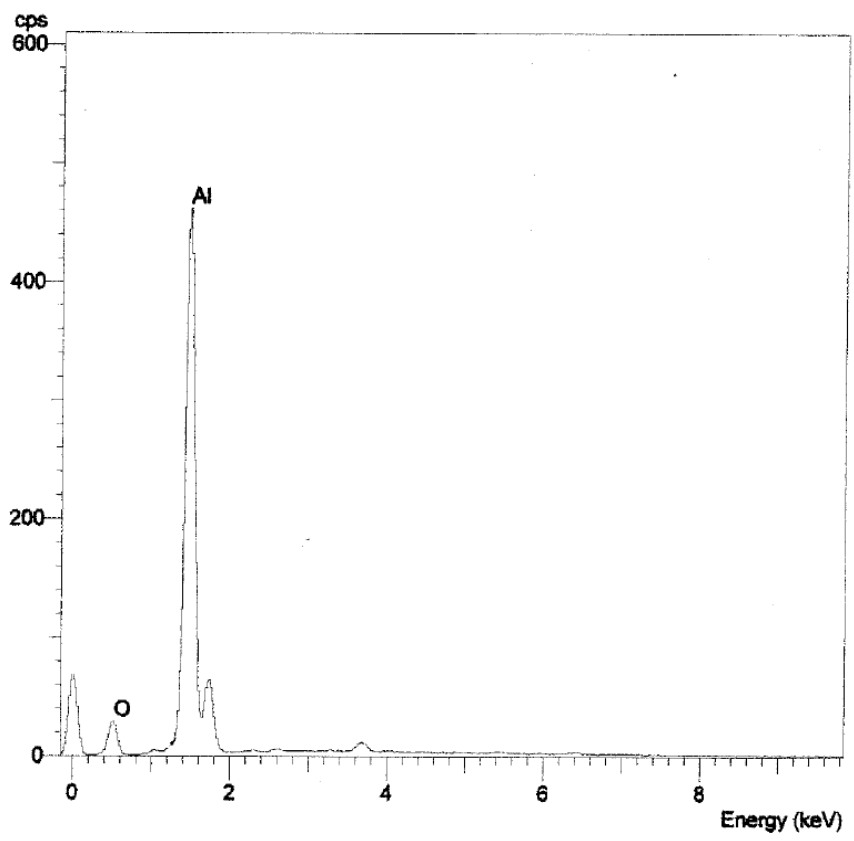

Fig. (7). EDS spectrum of clean Al sample.

\subsection{Mechanism of the Inhibition of Corrosion}

It appears from the experimental data that phenomenon of adsorption plays a fundamental role in inhibition process. This assumption is supported by the following explanation:

The value of $\mathrm{pH} z \mathrm{zh}$, which is defined as the $\mathrm{pH}$ at a point of zero charge, is equal to 9.1 for aluminum [11]. So aluminum surface is positively charged at $\mathrm{pH} \approx-0.28$, corresponding to $2 \mathrm{M} \mathrm{HCl}$. Therefore, $\mathrm{Cl}^{-}$and $\mathrm{IO}_{3}{ }^{-}$ions can be adsorbed on aluminum surface via their negative centers. In order to be able to predict the adsorption mechanism of these ions to positively charged aluminum surface, corrosion mechanism of aluminum in hydrochloric acid must be known [12]. According to this mechanism anodic dissolution of Al proceeds according to the following steps:

$\mathrm{Al}+\mathrm{Cl}^{-} \rightarrow \mathrm{AlCl}_{\text {ads }}^{-}$

$\mathrm{AlCl}_{\text {ads }}^{-}+\mathrm{Cl}^{-} \rightarrow \mathrm{AlCl}_{2}^{+}+3 \mathrm{e}^{-}$
The cathodic hydrogen evolution follows the steps:

$\mathrm{H}^{+}+\mathrm{e}^{-} \rightarrow \mathrm{H}_{\text {ads }}$ (fast)

$\mathrm{H}^{+}+\mathrm{H}_{\mathrm{ads}} \rightarrow \mathrm{H}_{2}$

$\mathrm{IO}_{3}^{-}$ads ions adsorbed on $\mathrm{Al}$ surface can interact with $\mathrm{AlCl}_{\mathrm{ads}}$ which are formed in step (1) according to:

$2 \mathrm{AlCl}^{-}{ }_{\text {ads }}+\mathrm{IO}_{3}{ }^{-}$ads $\rightarrow \mathrm{Al}_{2} \mathrm{O}_{3}+\mathrm{I}^{-}+2 \mathrm{Cl}^{-}$

\section{Rich Oxygen}

Thus the oxidation reaction of $\mathrm{AlCl}^{-}$ads to $\mathrm{AlCl}_{2}^{+}$as shown by step (2) can be prevented. This phenomenon is attributed to surface interactions with inhibitor molecules, resulting in greater surface coverage [13]. This enhances the inhibition efficiency considerably.

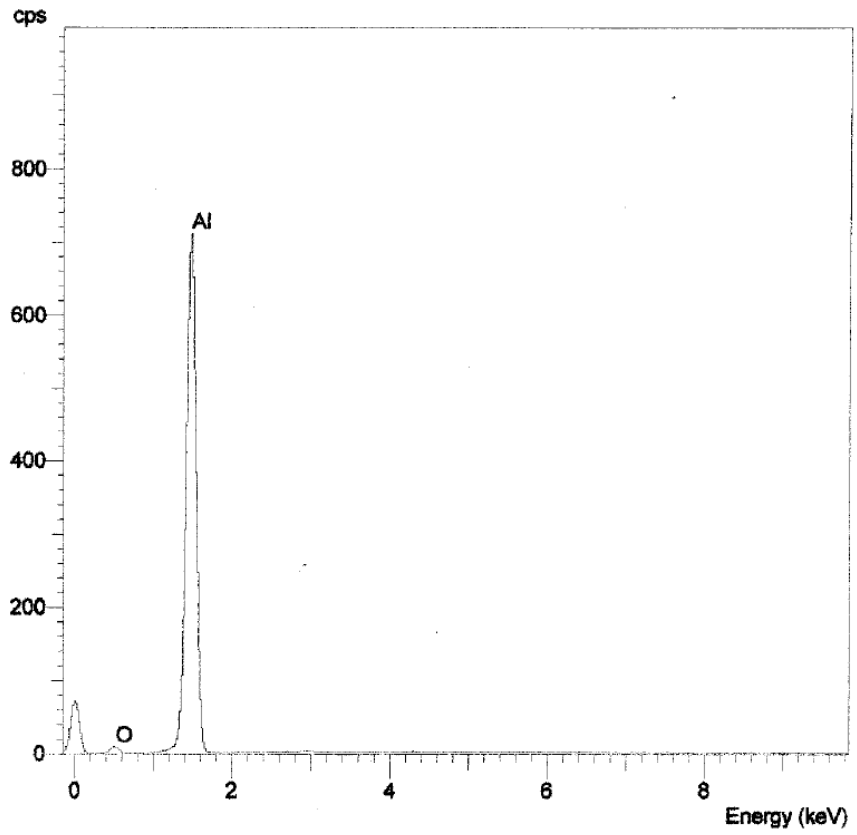

Fig. (8). EDS spectrum of Al sample in $2 \mathrm{M} \mathrm{HCl}$.

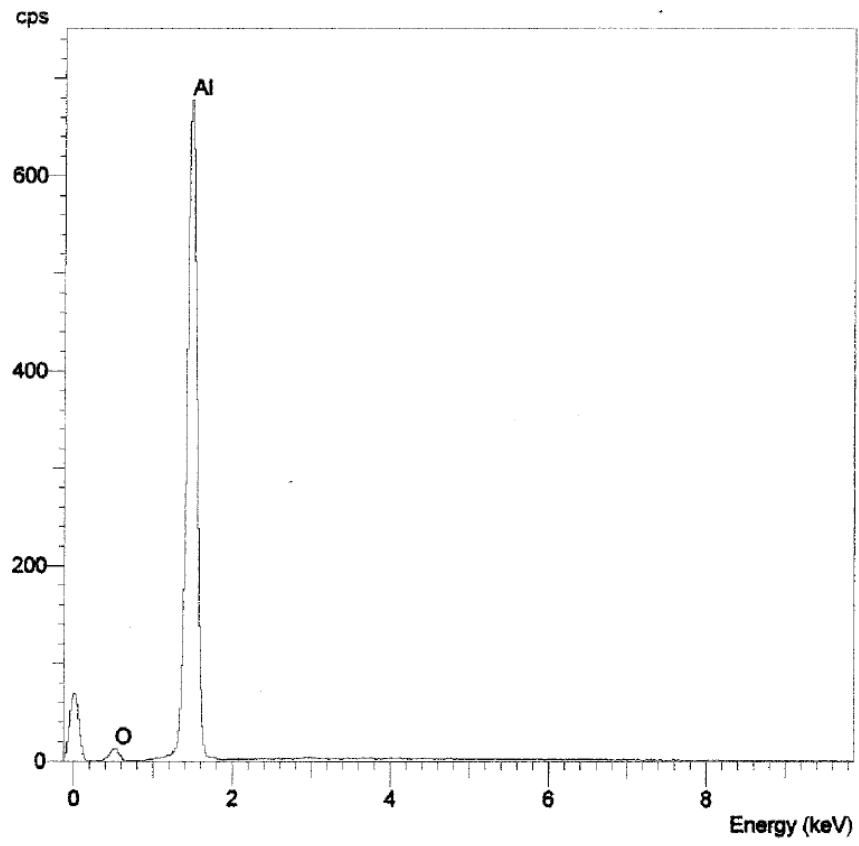

Fig. (9). EDS spectrum of $\mathrm{Al}$ sample in $2 \mathrm{M} \mathrm{HCl}$ in presence of 100 ppm $\mathrm{KIO}_{3}$ inhibitor. 


\section{4- CONCLUSION}

Surface analysis show that $\mathrm{IO}_{3}^{-}$formation on aluminum surface produce strong film which is compact, hard and protective. The inhibitor acts through adsorption phenomena and formation of barrier film. $\mathrm{KIO}_{3}$ can be used as an effective corrosion inhibitor for aluminum in $2 \mathrm{M} \mathrm{HCl}$ solution.

\section{REFERENCES}

[1] Hurlen T, Lian HH, Odegard OS, Valand TV. Corrosion and passive behaviour of aluminum in weakly acid solution. Electrochim Acta 1984; 29: 579- 85.

[2] Pourbais M. Atlas of electrochemical equilibra in aqueous solutions. New York; Pergamon Press, Oxford 1966.

[3] Fontana MG. Corrosion engineering. $3^{\text {rd }}$ edition, McGraw-Hill, International ed. New York, Chapter 5 1987; p. 237.

[4] Christopher MAB. On the electrochemical behaviour of aluminium in acidic chloride solution. Corrosion Sci 1992; 33: 203-10.

[5] Evans UR. An introduction to metallic corrosion. Edward Arnold, London 1983; p. 69.
[6] Abdel Kader JM, Shams El-Din AM. Efficiency of alkylamines and alkylammonium ions in retarding the dissolution of $\mathrm{Al}$. Corrosion Sci 1970; 10: 551-59.

[7] Sklarska S. Pitting corrosion of metals. NACE, Houston, Texas. On "Corrosion inhibitors". Ann Univ Ferrara, N.S., Sez. V. Suppl. N.P. 1173.

[8] Rozenfled IL. Corrosion inhibitors. New York, NY: McGraw Hill, International 1981; p. 97.

[9] Shibli SMA, Saji VS. Co-inhibition characteristics of sodium tungastate with potassium iodate on mild steel corrosion. Corrosion Sci 2005; 47: 2213-24.

[10] EL Maghraby AA. Corrosion inhibition of aluminum in hydrochloric acid solution using potassium iodate inhibitor. Open Corrosion J 2009; 2: 178-85.

[11] Natishan PM, McCaferty E, Hubler GK. The effect of zero charge on the pitting potential. J Electrochem Soc 1986; 133: 1061-62.

[12] Yurt A, Ulutas S, Dal H. Electrochemical and theortical investigation on the corrosion of aluminum in acidic solution containing some Schiff bases. Appl Surf Sci 2006; 253: 919-25.

[13] Umoren SA, Ebenso EE. The synergistic effect of polyacrylamide and iodide ions on the corrosion inhibition of mild steel in $\mathrm{H}_{2} \mathrm{SO}_{4}$. Mater Chem Phys 2007; 106: 387-93.

(C) A.A. El Maghraby; Licensee Bentham Open.

This is an open access article licensed under the terms of the Creative Commons Attribution Non-Commercial License (http://creativecommons.org/licenses/by$\mathrm{nc} / 3.0 /$ ) which permits unrestricted, non-commercial use, distribution and reproduction in any medium, provided the work is properly cited. 